\title{
Estudios de Costes en la Renta de la Pólvora de Nueva España Ante la Implantación de un Nuevo Sistema de Gestión (1766-1785)
}

\section{Miriam Núñez Torrado}

To cite this article: Miriam Núñez Torrado (2002) Estudios de Costes en la Renta de la Pólvora de Nueva España Ante la Implantación de un Nuevo Sistema de Gestión (1766-1785), Spanish Journal of Finance and Accounting / Revista Española de Financiación y Contabilidad, 31:111, 47-74, DOI: 10.1080/02102412.2002.10779444

To link to this article: https://doi.org/10.1080/02102412.2002.10779444

\section{曲 Published online: 15 Jan 2014.}

\section{Submit your article to this journal $\widetilde{ }$}

III Article views: 11

Citing articles: 3 View citing articles ๔ 


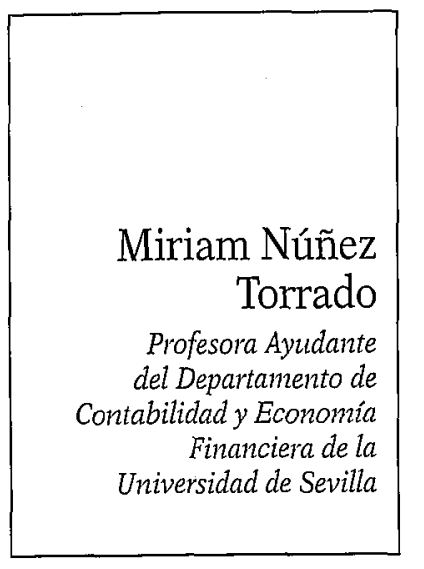

\section{ESTUDIOS DE COSTES} EN LA RENTA DE LA PÓLVORA
DE NUEVA ESPAÑA ANTE LA IMPLANTACIÓN DE UN NUEVO SISTEMA DE GESTIÓN (1766-1785)

Resumen.-Palabras clave.-Abstract.-Key words.-1. La renta de la pólvora en Nueva España.-2. Preámbulos a la administración directa.-3. La organización de la renta de la pólvora.-4. Estudios de costes en el nuevo sistema: 4.1. Primer estudio de costes. 4.2. Segundo estudio de costes. 4.3. Intento de inclusión del cálculo anual de costes en los informes de la renta. 5. A modo de resumen.-6. Bibliografía.

\section{RESUMEN}

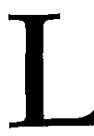

As reformas del Despotismo Ilustrado, características de la política española del siglo dieciocho, dieron lugar a la instauración de un rígido centralismo, provocando la homogeneización de la estructura política y administrativa de todos los reinos pertenecientes a la Corona española. Entre ellos se encontraba el virreinato de Nueva España, principal fuente de ingresos para la Corona. En el último tercio del siglo dieciocho se produjeron las grandes reformas fiscales del virreinato de Nueva España, consecuencia de la nueva política implantada por los Borbones. La principal actuación a este respecto fue incorporar a la gestión estatal directa los oficios públicos enajenados y las rentas arren- 
dadas. Este trabajo se centra en los estudios de costes surgidos en la renta de la pólvora de Nueva España a partir de 1766, consecuencia del creciente intervencionismo estatal a que se vió sometido dicho monopolio. Se tratará asimismo de explicar el fin y utilidad de esos estudios a la luz de las fuentes primarias consultadas en el Archivo General de Indias de Sevilla.

\section{PALABRAS CLAVE}

Siglo XVIII; Estudios de Costes; Renta de la Pólvora; Nueva España; Fuentes Primarias.

\section{ABSTRACT}

Enlightened Despotism reforms, common through Spanish policy in the Eighteenth Century, gave way to the establishment of a rigid centralism, provoking the homogenization of the political and economic structure of every kingdom belonging to the Spanish Crown. Among them was the Viceroyalty of New Spain: the Crown's principal source of income. In the last third of the Eighteenth Century the main fiscal reforms in the Viceroyalty of New Spain took place, as a consequence of the new policy implemented by the Bourbons. The main performance regarding such reforms was to incorporate the public careers sold and rented monopolies to the direct state control. This work focuses on the costs studies rose in New Spain gunpowder monopoly from 1766, as a consequence of the increasing state interventionism over such monopoly. We will also try to explain the aim and utility of these costs studies through the primary sources consulted in the General Archive of the Indies in Seville.

\section{KEY WORDS}

Eighteenth Century; Costs Studies; Gunpowder Monopoly; New Spain; Primary Sources. 


\section{ESTUDIOS DE COSTES EN LA RENTA DE LA PÓLVORA DE NUEVA ESPAÑA ANTE LA IMPLANTACIÓN DE UN NUEVO SISTEMA DE GESTIÓN (1766-1785)}

El presente estudio forma parte de un trabajo más amplio sobre el papel jugado por la contabilidad en el proceso de cambio organizativo experimentado por el monopolio de la pólvora a mediados del siglo XVIII. No obstante, nos vamos a centrar en el análisis de la emergencia de estudios de costes ante el cambio en el sistema de gestión de la renta.

Para realizar este estudio se han utilizado fuentes primarias y secundarias. Concretamente las fuentes primarias proceden del Archivo General de Indias [AGI], de la subsección de la quinta serie documental o serie de Gobierno conocida como Audiencia de México, con un total de 3.190 legajos.

\section{LA RENTA DE LA PÓLVORA EN NUEVA ESPAÑA}

La elaboración de pólvora en Nueva España comenzó poco después de que se conquistara la capital, México, pues para Hernán Cortés resultaba arriesgado vivir pendiente de los socorros de pólvora que se le enviaban desde la metrópoli. La pólvora se incorporó como ramo de Real Hacienda en 1569, y desde ese momento funcionó bajo el régimen de arrendamiento hasta el año de 1766 en que, a consecuencia de la visita de José de Gálvez (1), pasó a administrarse por parte de la Corona [Villar Ortiz, 1988].

A la llegada de Gálvez a Nueva España la mayor parte de las rentas estaban arrendadas a particulares. En el sistema de arrendamiento o asiento, característico del reinado de los Austrias, un particular se hacía cargo en exclusiva de la explotación de un determinado ramo de la Real Hacienda. A cambio de ello, el arrendatario o asentista debía entregar a la Corona una cantidad fija anual (en dinero y/o en especie). Pero este sistema resultaba lesivo tanto para los contribuyentes como para la hacienda. Los asen-

(1) Cuando Carlos III llegó al trono en 1759 y comprobó el desorden en que se encontraban las rentas y las cuentas de Indias, decidió enviar visitadores generales a esos territorios, destinando a Nueva España a Francisco de Armona. El fallecimiento de éste durante el viaje obligó al nombramiento de un nuevo visitador, que recayó en la persona de José de Gálvez [Arcila Farías, 1955]. 
tistas aprovechaban el desconocimiento oficial de lo que realmente producían las rentas para pujar en las subastas públicas de adjudicación de las mismas por cantidades muy bajas, en comparación con los rendimientos que ellos obtenían con su explotación. En los casos en que se veían obligados a pagar un canon elevado, o bien lo repercutían a los contribuyentes o bien disminuían la calidad de los productos que fabricaban, según se tratara del arrendamiento de la recaudación de un impuesto o de un estanco (2) de producción (como era el caso del ramo de la pólvora).

Al ser designado Gálvez como visitador general se le dió una instrucción reservada con fecha de 14 de marzo de 1765 . En ella se le pedía que agotase todos los medios a su alcance para maximizar el producto de las rentas, intentado evitar la creación de nuevas contribuciones y procurando que se pagaran los impuestos legítimos [AGI, México 1249]. La experiencia fiscal de la metrópoli había servido para consolidar la necesidad de sustituir a los arrendadores de rentas con el objetivo de aumentar los ingresos fiscales sin incrementar la base fiscal. Gálvez tenía que acometer una reforma económica rápida basada en una modificación de las formas recaudatorias: cambio del sistema de arrendamiento a una administración de las rentas de la Real Hacienda por parte de un funcionario público preparado y competente. Así, la mayoría de las rentas que estaban arrendadas a particulares pasaron a ser gestionadas directamente por la Corona, según una idea centralista de la Administración y en razón a una mayor eficacia.

La incorporación del ramo de la pólvora al control estatal directo tenía, a diferencia de las restantes rentas de la Real Hacienda de Nueva España, más implicaciones militares que económicas. La importancia de la pólvora residía sobre todo en la necesidad de disponer de ella en cantidad y con calidad suficientes en los puntos más conflictivos del virreinato (La Habana, Veracruz, Presidios Internos). Al encargarse por sí misma de la fabricación de pólvora, la Corona no sólo pretendía abastecer al ejército, sino también poder consumirla y suministrarla al público [especialmente a los mineros (3)] a precios más económicos que en la época de

(2) El estanco de un determinado género o manufactura consistía en el establecimiento del monopolio sobre el mismo. La Hacienda Real se constituía en el único fabricante autorizado, obteniendo de la venta de los productos estancados un beneficio extraordinario. Se distinguían dos tipos de estancos: de "producción" o monopolios de fabricación y distribución, como la pólvora, el tabaco o la sal, entre otros; y de «servicios» que el Estado creaba con el único objeto de obtener ingresos por esta vía, como el del papel sellado o la lotería [Artola, 1982].

(3) El uso de la pólvora en la minería, para facilitar las tareas extractivas, se generalizó en Nueva España a lo largo del siglo XVIII [Bargalló, 1955]. El virreinato se constituyó 
los asientos [AGI, México 1249]. La entrada en administración por la Corona de la renta de la pólvora se produjo a primeros de octubre de 1766, bajo la dirección del teniente coronel de infantería D. Nicolás Devis.

\section{PREÁMBULOS A LA ADMINISTRACIÓN DIRECTA}

A lo largo del siglo XVIII se produjeron dos intentos fallidos de pasar el ramo de la pólvora a la gestión estatal directa, el primero en 1757 y el otro en 1762. En estos momentos se empezaron a sentar las bases que posibilitarían que el posterior cambio en el sistema de administración se llevara a cabo de forma rápida e irreversible.

Las reiteradas quejas que llegaban al monarca, a través del Consejo de Indias, sobre la mala calidad de la pólvora de Nueva España y sus nefastas repercusiones (4), junto con los escasos rendimientos que producía su arrendamiento, dieron lugar a un primer intento, en 1757, de pasar el ramo a la gestión estatal directa. No obstante, dicho intento fracasó a los dos meses de su instauración, tras la oferta planteada por la persona designada para la dirección de la renta, D. Francisco Javier Paulín: se comprometía a arrendarla a un precio mucho mayor del que hasta entonces se había pagado por la misma y a suministrar información a la Hacienda Real sobre los rendimientos que producía el ramo. Defectos de forma en la concesión de este arrendamiento (sin que mediara subasta pública) dieron lugar a la pérdida del mismo por Paulín y a su adjudicación a D. Rodrigo Antonio de Neira.

El segundo intento se inició en 1762, a instancias del virrey Marqués de Cruíllas, ante las quejas manifestadas por los oficiales reales de Veracruz sobre la escasez y mala calidad de la pólvora que enviabal el

en el primer productor mundial de plata durante dicho siglo. El término "minero" se refería al empresario de minas, que invertía capital para la explotación de un determinado yacimiento [AGI, México 2235].

(4) La pérdida de La Habana en 1762 a manos de los ingleses se atribuía a la mala calidad de la pólvora fabricada en Nueva España. Así se aprecia en una Real Orden de 11 de febrero de 1763 dirigida al entonces virrey Marqués de Cruíllas:

«No obstante que son reiteradas las órdenes a ese virreinato para que vigile la buena calidad de la pólvora y que a V.E. se le previno también ulteriormente sobre lo mismo por muy particular encargo de S.M., subsiste siempre en Su real ánimo tocado de los ejemplos funestos que han experimentádose en lo pasado, así en funciones de mar como de tierra y en el más doloroso de dicha Habana, a cuya pérdida contribuyó mucho la mala calidad de la pólvora, por el poco efecto que se perdía en los tiros de su defensa» (el subrayado se ha añadido) [AGI, México 2450]. 
asentista desde México, con destino a La Habana y a las Islas de Barlovento. La guerra que en ese momento enfentaba a España contra los ingleses (Guerra de los Siete Años) hacía más acuciante la necesidad de pólvora abundante y de calidad. Esas circunstancias impulsaron al virrey Cruíllas a emitir un decreto mediante el cual posibilitaba el intervencionismo estatal en la organización de la renta de la pólvora y en las labores productivas [AGI, México 2228]. Ello permitió adquirir un conocimiento de la renta del que hasta entonces se había carecido (5), creándose de esta forma las condiciones idóneas hacia el cambio en el sistema de gestión. Aunque el virrey Cruíllas rescindió el contrato del último asentista (Neira) para establecer el nuevo sistema de administración de la renta en enero de 1766, el cambio fue anulado por el visitador Gálvez, que devolvió el asiento a Neira hasta la finalización de su contrato de arrendamiento. Sólo al término de éste se produjo la instauración de la nueva estructura organizativa de la renta de la pólvora, a primeros de octubre de 1766.

\section{LA ORGANIZACIÓN DE LA RENTA DE LA PÓLVORA}

La fabricación de pólvora se realizaba desde 1600 en una única fábrica construida para tal fin en el Real Sitio de Chapultepec, a las afueras de México. De esta forma la ciudad quedaba fuera de peligro en caso de incendios, bastante frecuentes en el proceso productivo de la pólvora. Durante la época de los asientos (1569-1766) la fábrica, aunque era de propiedad real, se arrendaba junto con la renta al asentista. Éste, durante los años que duraba su contrato, era el encargado de toda su organización y quien tenía jurisdicción completa en todas sus dependencias (6). Solamente el virrey, como autoridad suprema, tenía poder para organizar una visita a la misma cuando lo consideraba oportuno, con el fin de analizar su funcionamiento [Villar Ortiz, 1988].

(5) Los asentistas forzaban las negociaciones de los contratos de arrendamiento de la renta con el fin de evitar suministrar la máxima información posible a la Corona sobre el funcionamiento de la renta o los rendimientos proporcionados por la misma.

(6) El asentista controlaba la fabricación de pólvora, refinamiento de sus ingredientes, horas de trabajo de los operarios, utilización de las dependencias de la fábrica y medidas de vigilancia y policía para evitar el contrabando, por citar algunos de los aspectos incluídos en su jurisdicción (Contrato de arrendamiento de la renta de la pólvora a favor del Capitán Juan de Alvarado, 1 de julio de 1687; AGI, México 1013]. 
Pero la factoría mexicana de Chapultepec se quedó anticuada, y fue preciso proyectar una nueva a finales de 1778 en el valle de Santa $\mathrm{Fe}$ [González Tascón, 1992]. La nueva fábrica entró en funcionamiento en 1782. Se destinó entonces la de Chapultepec al refinamiento de salitre -principal materia prima en el proceso productivo de la pólvora- y a la fabricación de pólvora en los casos en que la producción de Santa Fe resultaba insuficiente -esto ocurría con bastante frecuencia, sobre todo en épocas de guerra y cuando se producía el incendio de algún molino en Santa Fe [AGI, México 2216].

Una vez que se estableció el régimen de administración estatal directa en la renta de la pólvora, la estructura y procedimientos organizativos tenían que ajustarse estrictamente a lo reglamentado en la Instrucción y Ordenanza elaborada por José de Gálvez a 15 de septiembre de 1766 para tal fin. Así lo señalaba el artículo 21 de la misma, según el cual «... se previene que en lo sucesivo se ha de observar puntualmente en la fábrica el método que prescribe la Instrucción reservada que a este fin se ha extendido, sin que por motivo alguno permita el Oficial de Artillería Veedor (7) que se contravenga a lo prevenido en dicha Instrucción, ni que se altere o varíe el método acordado con todo conocimiento...» [AGI, México 2216].

La Ordenanza de Gálvez constaba de 57 artículos que regulaban de manera detallada los aspectos relacionados con la estructura organizativa de la renta de la pólvora. En una serie de capítulos se daba una organización completa al régimen de gobierno de la fábrica y ramo de la pólvora. En la cúspide de la jerarquía estaba el "Director General de la Renta y Estanco de la Pólvora en el Reino de Nueva España», autoridad máxima que respondía ante el Superintendente General de Hacienda. El director tenía jurisdicción en lo referente al régimen económico de la renta, empleados, demandas civiles y militares en que estuvieran estos empleados y asuntos de contrabando. A sus órdenes estaban el contador, el tesorero y el administrador de la fábrica. Estos puestos de responsabilidad debían ser ejercidos por funcionarios públicos preparados y profesionalmente competentes -imperaba el criterio "Pro virtute et merito", lema de la Orden de Carlos III.

El cargo de contador era el segundo en importancia tras el de director «de cuyas facultades usará en sus enfermedades o ausencias» [art. 6 de la Ordenanza de la Pólvora; AGI, México 2216]. Su misión principal era el

(7) Militar encargado de la supervisión del proceso productivo, para que se siguiera según las especificaciones. 
control de la recaudación y la disposición de los bienes de la renta. Se debía por tanto encargar de «la liquidación, reconocimiento y glosa» de las cuentas de la renta [art. 6]. Para ello no sólo tenía que asentar las partidas en los libros correspondientes, sino que además debía ordenarlas y glosarlas (8) antes de enviarlas al Tribunal de Cuentas de Nueva España para ser inspeccionadas.

Al tesorero le correspondían los aspectos relacionados con la entrada y salida de caudales de la caja, es decir, el cobro de todo lo producido por las ventas de pólvora y sus componentes y por confiscaciones y la realización de pagos ocasionados por la compra de materias primas y auxiliares, jornales de operarios, sueldos de empleados y libranzas del director autorizadas por la contaduría de la renta [art. 7].

A cargo del administrador quedaba el cuidado y gestión de la fábrica, y de él dependía que la pólvora fabricada fuese de la máxima calidad. Debía, por tanto, controlar al detalle el proceso de fabricación, evitando desviaciones con respecto a lo reglamentado. También debía vigilar la calidad de los materiales utilizados mediante su intervención directa en la compra de los mismos. Para facilitar su misión se crearon los puestos de oficial de libros y escribiente, encargados del control de entrada y salida de materiales y de la anotación diaria de los gastos ordinarios y extraordinarios de la fábrica, bajo la supervisión directa del administrador [art. 8 y 42].

(8) La glosa consistía en comprobar que los cargos y datas de los libros preceptivos se habían realizado conforme a las leyes establecidas [Donoso Anes, 1996]. 
FIGURA 1

RÉGIMEN DE GOBIERNO Y RECURSOS HUMANOS EN LA RENTA DE LA PÓLVORA

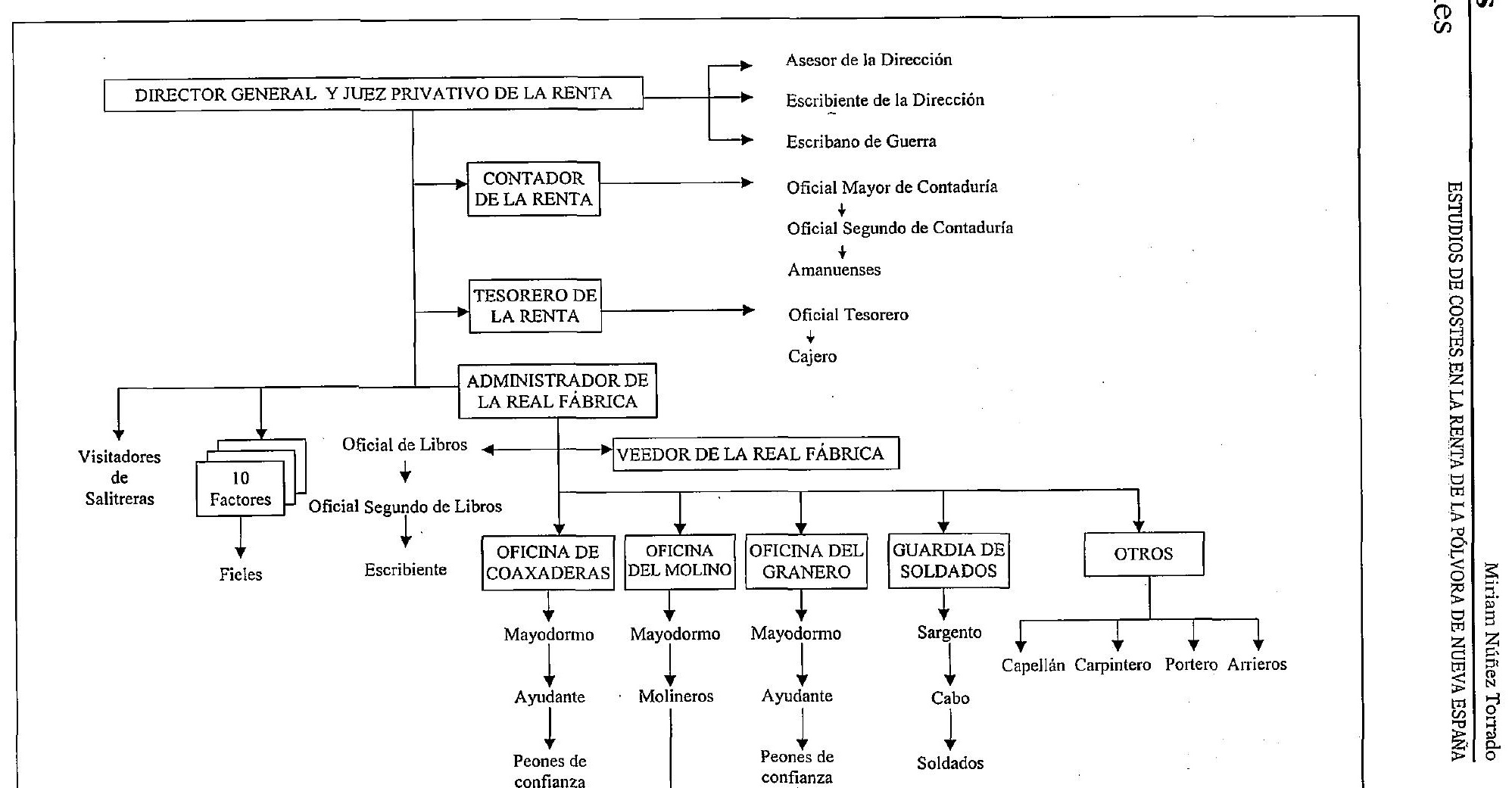


El proceso productivo seguido para la fabricación de pólvora variaba en función del destino que se le fuera a dar a la misma: usos militares, la llamada Pólvora del Rey, o venta al público, la Pólvora del Común. Las fases centrales del proceso eran, por orden funcional, tres: trituración, empaste y graneo. Éstas no podían iniciarse hasta que las materias primas principales (salitre, azufre y carbón) cumplieran ciertos requisitos cualitativos que garantizasen el éxito del producto final. Por tanto, se les sometía a unos procesos previos que variaban en función del ingrediente de que se tratara y del uso que se le fuera a dar al mismo (los llamados ensayes para la evaluación de la calidad de las materias primas; también se realizaban ensayes para comprobar la calidad del producto terminado - la pólvora-). 
FiguRA 2

EL PROCESO PRODUCTIVO

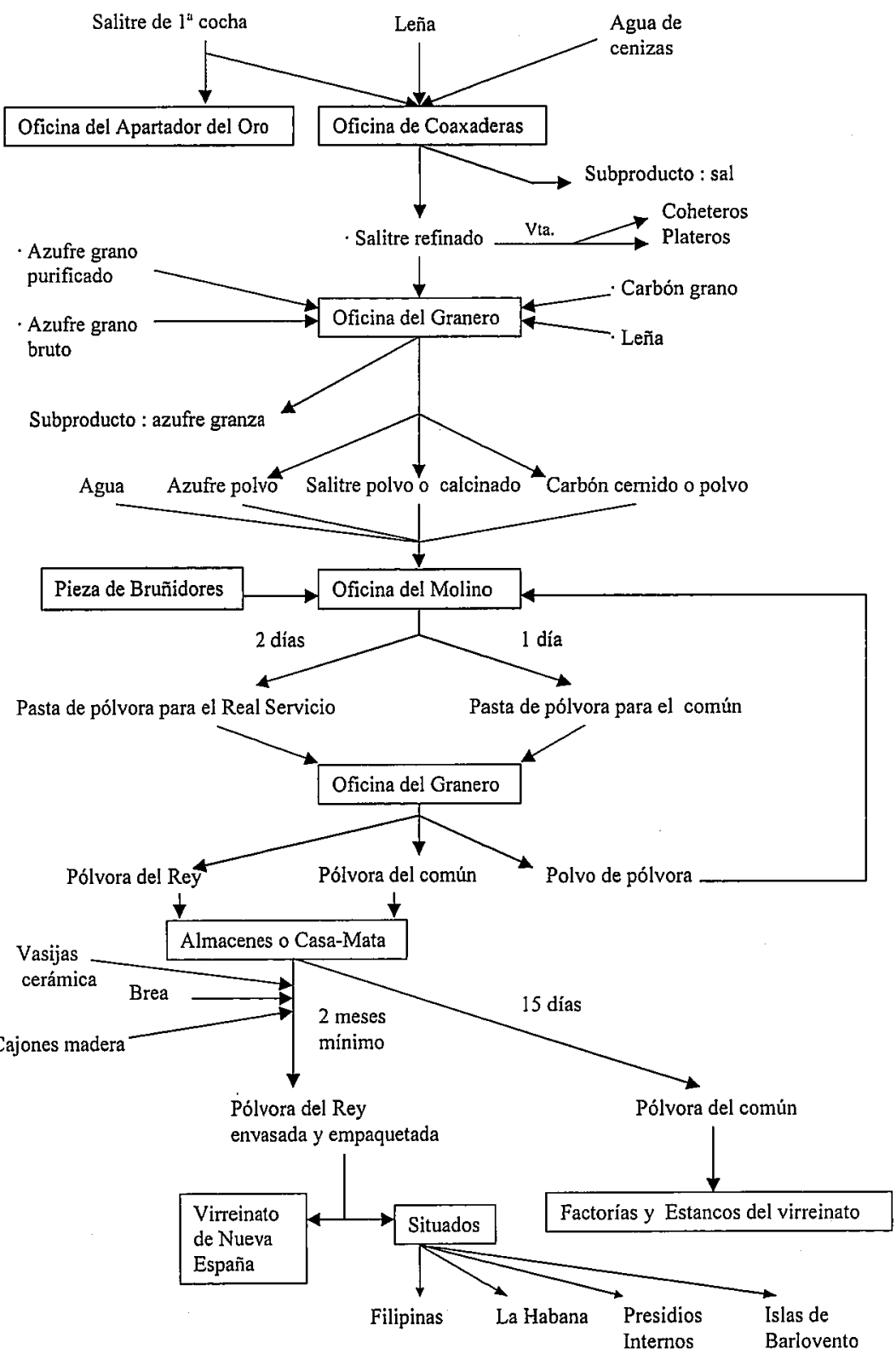




\section{ESTUDIOS DE COSTES EN EL NUEVO SISTEMA}

A partir de la instauración del régimen de administración directa en octubre de 1766 se empezó a realizar un control exhaustivo de los caudales que entraban y salían de la tesorería, en razón a qué conceptos, y de los materiales inventariables pertenecientes a la renta. Las cuentas de la renta se empezaron a llevar según el método de Cargo y Data o partida simple, que consistía en cargar todas las sumas que se habían recibido, abonando a continuación todas las que se habían gastado o entregado [Hernández Esteve, 1992]. Éste era el método prescrito desde 1596 para llevar las cuentas de la administración pública hasta 1784 , fecha en que se intentó la introducción del método de partida doble o del Debe y Haber en las cajas reales de Indias [Donoso Anes, 1996].

La renta de la pólvora estaba obligada a rendir cuentas ante la Superintendencia General de Hacienda de Nueva España al término de cada ejercicio económico, que coincidía con el año natural. Para ello se debían enviar los informes financieros pertinentes al Tribunal de Cuentas de Nueva España, donde se realizaba la revisión de los mismos (conocida como «toma de cuentas»). Finalizada ésta, dichos informes se remitían al Consejo de Indias «... para la noticia general que conviene tener, y lo demás, que fuere necesario proveer...» [Recopilación de Leyes de Indias, libro $8 .^{\circ}$, título $1 .^{\circ}$, ley 46]. Del estudio de estos informes financieros (que excede el contenido de este artículo) se deduce la finalidad de los mismos: el control de la renta y la rendición de cuentas ante instancias superiores.

La realización de análisis sobre costes no constituye un hecho sistemático en la renta de la pólvora en el período considerado. No obstante, en determinados momentos y por causas concretas se llevaron a cabo este tipo de estudios, generalmente con el fin de justificar la adopción de una cierta decisión.

\subsection{Primer Estudio de Costes}

En 1771 y desde su reciente destino en La Habana, en calidad de comandante e inspector de Artillería de la Isla de Cuba, D. Nicolás Devis presentó ante el Ministro de Indias D. Julián de Arriaga una relación de veinticinco documentos numerados «... para su defensa» [AGI, México 2228]. Pretendía con ello restablecer su profesionalidad, puesta en entre- 
dicho por los que propiciaron su marcha de la renta. Entre esos documentos se encuentran, con el número 2:

«Unas diligencias originales en cuatro hojas por las que se demuestra que en los quince primeros meses de administrarse la renta de pólvora de cuenta de la Real Hacienda, se construyó mucho más de esta Munición, a proporción de los salitres consumidos, que en el año de 1765, en que corría aún dicha renta de cuenta del Asentista Don Rodrigo de Neira.»

Devis atribuía las mejoras en el proceso productivo, con reducción de los costes de fabricación de la pólvora, a la calidad de los salitres empleados. Esa calidad dependía en buena parte del estado en que los salitreros suministraran el salitre de primera cocha o en bruto a la fábrica. De ahí que considerase apropiado pagar un mayor precio por el salitre, manifestándose así en contra «... del mal entendido ahorro del último Asentista Don Rodrigo de Neira en pagar este ingrediente a bajo precio» [AGI, México 2228]. De este modo conseguía un salitre de superior calidad con el que se podían fabricar un mayor número de libras de pólvora. Por tanto, el incremento del coste de la principal materia prima no incidía en un aumento del coste de producción de la pólvora, sino que el efecto era el contrario, en virtud a la mayor eficiencia del proceso.

Además de aumentar el precio del salitre, Devis instruyó a los salitreros sobre el modo de beneficiarlo con objeto de que la calidad de dicho ingrediente aumentara, pues «... el ver la mala calidad de Salitres que venían a la fábrica de Pólvora en tiempo del citado Asentista, me hizo conocer cuán preciso era instruir formalmente a los Salitreros, y éste fue mi principal conato luego que se me encargó la dirección de dicha fábrica, puesta de cuenta de S.M., ya tratando con los mismos cuando se me presentaban muestras de este Ingrediente, y ya con instrucciones por escrito y de palabra» [AGI, México 2228].

Al constituir el salitre la principal materia prima en la elaboración de la pólvora, Devis atribuía los principales ahorros de costes y mejoras de la productividad a este ingrediente. Reconocía las siguientes partidas de gastos, pero no especificaba cuáles tenía en cuenta para la determinación del coste de producción de la pólvora: salitre, azufre, carbón, leña, atún para los refinos, enseres [como «jerga, guangoches (9), petates o esteras para las coladeras, cubetas para el transvase de cocimientos y lejías y otros utensilios»], renovación y recomposición de calderas, sueldos de

(9) Jerga: pieza de paño que se coloca sobre el lomo de las cabalgaduras. Guangoche: Tela basta, especie de arpillera para embalajes, cubiertas, etc. [Marín, 1982]. 
empleados de la renta y de jornaleros de la fábrica, manutención de mulas y, por último, "otros gastos extraordinarios de muy corta entidad, como libros, papel, tinta, etc." [AGI, México 2228].

La mejor calidad de los salitres influía en varios de esos gastos. Daba lugar a un menor consumo de leña, de atún, de enseres, a un menor gasto de renovación y recomposición de calderas y a ahorros en los jornales de los operarios. En cambio, no influía en el azufre, en el carbón, en la manutención de las mulas, ni en el "casual y pequeño gasto de tinta, papel, libros, etc.».

A través de sus cálculos, Devis trató de demostrar:

a) Las mejoras en la eficiencia logradas con su gestión; para ello analizó la evolución de la relación outputs/inputs, comparando los quince primeros meses de administración directa (de octubre a diciembre de 1766 y el año 1767), con 1769, su último año completo en la renta.

b) La mayor productividad conseguida en los quince primeros meses de gestión estatal, frente al último año de asiento.

\section{a) Análisis de la gestión de Devis (1766-1769)}

Para la demostración primera, se basó en «el cotejo de los Cargos y Datas de Salitres y su costo (según los Libros de Administración) verificados en los quince primeros meses de Administración Real y en los doce del año de 1769, prenscindiendo de lo ocurrido en el año de 1768 , en el que también hubo ventajas respecto a los quince referidos meses».

En el 66 y 67 se realizaron 541 tareas de refinación, en cada una de las cuales se emplearon 16 quintales (10) de salitre, lo que daba un total de salitre de primera cocha consumido de 8.656 quintales. Con dicha cantidad de salitre bruto se originaron 3.137 quintales y 80 libras de salitre refinado. De modo que en cada operación de refinación se produjeron 5 quintales y 80 libras de salitre refinado o calcinado (rendimiento del proceso obtenido de dividir 3.137 quintales y 80 libras de calcinado entre las 541 tareas realizadas).

En el año 69 se realizaron un menor número de tareas de refinación, 372, en las que se consumieron 5.952 quintales de salitre bruto (a razón de nuevo de 16 quintales la tarea). Con esa cantidad de salitre de primera cocha resultaron 3.199 quintales y 11 libras de salitre beneficiado, por lo

(10) 1 quintal $=100$ libras aprox.; 1 libra $=16$ onzas; 1 onza $=28,7$ gramos. 
que el rendimiento de cada tarea fue aproximadamente de 8 quintales y 60 libras de salitre calcinado. De manera que, a igualdad de inputs, 16 quintales de salitre de primera cocha por tarea de refinación, se produjeron mayores outputs en el año 1769 que en los quince primeros meses de gestión directa: 8 quintales y 60 libras frente a 5 quintales y 80 libras. El rendimiento del proceso de refinación en el primer período fue de aproximadamente el 37 por 100, mientras que en el segundo llegó casi al 54 por 100 . Según Devis, esto se debió a que «... los salitres se mejoraron y no mermaron tanto en su beneficio; en el año 1768 fueron mejores, en el de 1769 más, y así sucesivamente va creciendo la ventaja de un año respecto a otro, hasta que tenga su límite, y que las malas estaciones no impidan el progreso» [AGI, México 2228].

También calculó el coste unitario del salitre calcinado o refinado resultante de los procesos, siendo inferior en 1769 que en el primer período, a pesar de que entonces el precio del salitre bruto era superior. El único componente del coste del salitre refinado que consideró fue el coste del salitre de primera cocha, sin tener en cuenta el coste de la leña consumida en el proceso de refinación o los jornales de los operarios de la oficina de coaxaderas (11).

El coste de los 16 quintales de salitre bruto que se empleaban en una tarea era de 162 pesos (12), 5 reales y 4 granos en los quince primeros meses, y de 180 pesos, 5 reales y 4 granos en 1769 . Como una tarea en el primer período daba lugar a 5 quintales y 80 libras de salitre calcinado, con un coste de 162 pesos, 5 reales y 4 granos (considerando sólo el coste del salitre bruto), entonces se podía calcular el coste de 1 quintal de salitre refinado, mediante una sencilla regla de tres. Éste resultó ser de 28 pesos y 4 granos.

En 1769, al ser el rendimiento de la tarea superior, 8 quintales y 60 libras de calcinado, aun siendo el coste de la misma superior, de 180 pesos, 5 reales y 4 granos, el coste del quintal de salitre calcinado resultó ser inferior al de los quince primeros meses en 7 pesos y 3 granos. Es decir, el coste del salitre calcinado fue de 21 pesos y 1 grano el quintal.

La Tabla 1 resume los conceptos previamente explicados:

(11) Dependencia de la fábrica donde se refinaban o beneficiaban los salitres comprados a los salitreros, para su incorporación a la pólvora como salitre refinado o calcinado.

(12) 1 peso $=8$ reales $=3$ tomines aprox. ; 1 tomín $=2,7$ reales aprox. $=12$ granos. 
TABLA 1

\begin{tabular}{|c|c|c|}
\hline Conceptos & $1766-1767$ & 1769 \\
\hline (a) n. ${ }^{\circ}$ de tareas & 541 & 372 \\
\hline (b) salitre bruto por tarea & 16 quintales & 16 quintales \\
\hline $\begin{array}{l}\text { (c) total salitre bruto consu- } \\
\text { mido (c) }=(\mathrm{a}) \mathrm{x}(\mathrm{b})\end{array}$ & 8.656 quintales & 5.952 quintales \\
\hline (d) coste total salitre bruto & 87.912 pesos 6,5 reales & 72.500 pesos 6 reales \\
\hline $\begin{array}{l}\text { (e) n. } .^{\circ} \text { de unidades compra- } \\
\text { das salitre bruto }\end{array}$ & 8.653 quintales 14 libras & 6.420 quintales 70 libras \\
\hline $\begin{array}{l}\text { (f) coste unitario salitre } \\
\text { bruto (1 quintal) }(\mathrm{f})=(\mathrm{d}) \\
\text { /(e) }\end{array}$ & 10 pesos 1 real 4 granos & 11 pesos 2 reales 4 granos \\
\hline $\begin{array}{l}\text { (g) coste salitre bruto por ta- } \\
\text { rea }(\mathrm{g})=(\mathrm{b}) \mathrm{x}(\mathrm{f})\end{array}$ & 162 pesos 5 reales 4 granos & 180 pesos 5reales 4 granos \\
\hline $\begin{array}{l}\text { (h) salitre calcinado por ta- } \\
\text { rea }\end{array}$ & 5 quintales 80 libras & 8 quintales 60 libras \\
\hline $\begin{array}{l}\text { (i) coste salitre calcinado } \\
\text { por tarea }(\mathrm{i})=(\mathrm{g})\end{array}$ & 162 pesos 5 reales 4 granos & 180 pesos 5 reales 4 granos \\
\hline $\begin{array}{l}\text { (j) coste unitario salitre cal- } \\
\text { cinado (1 quintal) (j) }= \\
\text { (i) } /(\mathrm{h})\end{array}$ & 28. pesos 4 granos & 21 pesos 1 grano \\
\hline $\begin{array}{l}\text { (k) total salitre calcinado (k) } \\
=(\mathrm{a}) \mathrm{x}(\mathrm{h})\end{array}$ & 3.137 quintales 80 libras & 3.199 quintales 20 libras \\
\hline $\begin{array}{l}\text { (l) coste total salitre calci- } \\
\text { nado }(\mathrm{l})=(\mathrm{k}) \times(\mathrm{j})\end{array}$ & 87.989 pesos 1 real 1 grano & 67.449 pesos 6 reales 4 granos \\
\hline
\end{tabular}


De la comparación de las columnas de la última fila de la Tabla 1 se concluye afirmando, como hizo Devis, que la Real Hacienda resultó aventajada en aproximadamente 20.540 pesos en el año 1769 , con respecto a los quince primeros meses de gestión directa. Esto fue posible gracias a las mejoras en el proceso de refinación del salitre en la fábrica y a la superior calidad del entregado por los salitreros.

$\mathrm{Al}$ ahorro anterior se sumaban otros de menor cuantía, pero que habría que incluir en este apartado por su relación con la superioridad cualitativa alcanzada por el salitre:

1. La mejor calidad del salitre bruto originaba, tras el proceso de refinación y la obtención del salitre calcinado, unas lejías superiores, de cuyo cocimiento se extraía otro salitre. A ese nuevo salitre se le denominaba "vulgarmente Salitre de coheteros, por expenderse a los de este arte en el estanco de México a 4 reales la libra». Con la mejora del salitre bruto Devis calculaba que se obtendrían cada año 50 quintales más del de coheteros, que multiplicados por su precio darían al Rey 2.500 pesos más al año.

2. Gracias a la superioridad del salitre bruto, en 1769, con 169 tareas de refinación menos, se produjo prácticamente la misma cantidad de salitre calcinado (ver fila (k), tabla 1). Como en cada tarea se consumían 10 cargas (13) de leña, a razón de real y medio la carga, el Rey se ahorró en 1769 por este concepto 316 pesos y 7 reales. Aunque Devis no incluyó el coste de la leña en los cálculos precedentes recogidos en la tabla 1, en cambio sí lo tuvo en consideración en este apartado.

3. El atún se empleaba durante el beneficio del salitre, para ayudar a la precipitación de las impurezas del mineral. Se utilizaban 2 libras de atún por cada tarea. Al realizarse en 1769169 tareas menos que en los quince primeros meses, el ahorro fue de 338 libras de este ingrediente. El atún costaba 9 pesos la arroba (14), con lo que la Real Hacienda se ahorró aproximadamente 112 pesos y 5 reales.

4. En la refinación del salitre se utilizaba utillaje, del tipo de telas gruesas para las coladeras (a modo de filtros), cubetas y otros utensilios. Gracias a que en 1769 se realizaron 169 tareas menos, "... no tuvieron tanto uso los referidos utensilios, y por consiguiente no hubo tanto consumo de ellos». Por tanto, el ahorro para el Rey fue el del valor de reposición de estos enseres (no lo cuantifica).

(13) 1 carga $=138,074 \mathrm{~kg}$.

(14) 1 arroba $=25$ libras $=11,506 \mathrm{~kg}$. 
5. Otro ahorro derivado de la buena calidad de los salitres, gracias a la cual el número de tareas en 1769 se había reducido, era el referente a los gastos de renovación y recomposición de las calderas. Así lo manifestaba Devis:

"La renovación y recomposición de calderas de refinación, causada por el continuo tormento del fuego, es un asunto costoso al Rey, no sólo en el pago de caldereteros, merma de metales, sino también en el gasto de peones para sacar y poner en sus respectivos puestos las citadas calderas, y en el del Oficial de Albañil para tapiarlas. Y habiéndose ejecutado 169 refinos menos en el año de 1769 , es consiguiente que no se habrán deteriorado tanto como en los expresados quince meses, y no se habrá ocasionado tanto gasto al Rey en esta parte.»

Se tenía, por tanto, en cuenta lo que hoy se conoce como depreciación funcional de los inmovilizados de la oficina de coaxaderas, y los factores que la provocaban. Como los elementos del inmovilizado se registraban en un inventario de enseres, independiente de los informes financieros de la renta, no existía ningún mecanismo contable que vinculara el coste ocasionado por la depreciación del inmovilizado con el valor en inventario del mismo. Tan sólo se registraba la renovación de las calderas a coste de reposición, como gasto del período en que se había producido.

6. También se derivaban ventajas relacionadas con los costes de personal. En 1769, al realizarse 169 tareas menos, se necesitó menos personal que en los quince primeros meses de gestión directa, con el consiguiente ahorro en jornales. No obstante, Devis no llegó a cuantificar ese ahorro, es decir, no llegó a expresar el número de operarios que sobraban, ni los jornales que les correspondían.

7. La última ventaja que Devis atribuía a la mejora en la calidad de los salitres se relacionaba con los costes indirectos de producción. En un año se utilizaron 8.000 quintales de salitre de primera cocha para producir 4.000 quintales de pólvora, por las mermas que experimentaba el salitre en el proceso productivo. Es decir, el rendimiento del salitre fue del 50 por 100. En otro año, en cambio, la mejor calidad del salitre hizo que se fabricasen 5.000 quintales de pólvora; el rendimiento fue entonces del 62,5 por 100 . El coste de producción de la pólvora resultó en este segundo caso inferior al primero, pues a mayor número de unidades producidas los costes 
de administración unitarios disminuían. Devis lo expresó de la siguiente forma:

«... Si se hace el cálculo para averiguar cuánto tuvo de costo al Rey cada quintal de esta munición, ha de resultar precisamente al Rey más barata en el año en que se labró más cantidad, [...], porque habiéndose de incluir en el total de gasto de construcción el importe de Salarios de Dependientes de Plaza fija, y el de los empleados en la cuenta y razón (15), quedará este gasto subdividido en más número de quintales de Pólvora, y no le cabrá a tanto por quintal, como en el año en que se labró menor cantidad" (el subrayado se ha añadido) [AGI, México 2228].

\section{b) Comparación asiento-gestión directa con Devis (1765-1767)}

El otro tema tratado por Devis fue la mayor productividad lograda en los quince primeros meses de su administración, en relación con el último año (1765) en que la renta estuvo a cargo de asentista. A pesar de encontrarse la renta en régimen de arrendamiento, se dispone de datos de producción de 1765, debido al intervencionismo estatal de la última época de los asientos.

Del Libro de Cargo y Data de la Administración, se extrajo que en los quince meses primeros bajo la dirección de Devis se consumieron 8.768 quintales y 47 libras de salitre de primera cocha, con los que se construyeron 4.394 quintales y 64 libras de pólvora en grano. En una diligencia jurídica practicada en 1765 con motivo del citado intervencionismo estatal, constaba que se había consumido en todo el año la cantidad de 6.847 quintales y 89 libras de salitre, en la fabricación de 2.374 quintales y 37 libras de pólvora.

Para hacer comparables los dos momentos (asiento y administración real) Devis tuvo que inferir qué cantidad de pólvora se hubiera fabricado en tiempos del asentista, con la cantidad de salitre consumido en la administración estatal. Esto lo hizo en una apartado de su informe al que llamó «cotejo», a través de una regla de tres:

«Si el Asentista con 6.847 quintales 89 libras de Salitre de primera cocha labró 2.347 quintales 37 libras de Pólvora; con 8.768 quintales 47 libras del mismo Salitre que se consumieron en los quince referidos meses de Administración Real, ¿cuánta pólvora hubiera

(15) Los dependientes de plaza fija eran los empleados de la renta. Los empleados en la cuenta y razón eran especificamente los empleados de la contaduría de la renta. 
fabricado? Y hecha la proporción le hubieran resultado 3.040 quintales 29 libras de Pólvora...» [AGI, México 2228].

Esos 3.040 quintales 29 libras de pólvora eran ya comparables con los 4.394 quintales 64 libras obtenidos en los quince meses de gestión directa (en ambos casos se había considerado la misma cantidad de inputs, esto es, de salitre de primera cocha consumido, gracias a la homogeneización). Por tanto, la comparación resultaba favorable a la administración real, pues a igualdad de inputs, los outputs, o cantidad de pólvora fabricada, fueron superiores en 1.354 quintales 35 libras. Es decir, la eficiencia del proceso productivo aumentó en algo más de un 15 por 100 con la gestión estatal.

Devis consideraba que, con el paso del tiempo, conforme se fueran familiarizando con todas las vicisitudes del proceso productivo, los rendimientos irían en aumento. Es decir, lo que actualmente conocemos como curva de la experiencia daría mejoras en la eficiencia en los años siguientes: «... sucesivamente va creciendo la ventaja de una año respecto a otro, hasta que tenga su límite...» [AGI, México 2228].

\subsection{Segundo Estudio de Costes}

Uno de los frentes de la guerra que enfrentó a España e Inglaterra en 1779 se encontraba en las provincias de Ultramar. La defensa del Golfo de México hacía necesaria la provisión de pólvora abundante en los puntos más conflictivos del virreinato de Nueva España. En 1781, el Virrey Martín de Mayorga comisionó al coronel Melchor Vidal de Lorca para que consiguiera que se abasteciera el puerto de Veracruz con 5.000 quintales de pólvora para los primeros días de 1782 [AGI, México 2216] (16). La situación en ese momento era delicada: tenía que haber finalizado la construcción de la fábrica de Santa Fe, pero retrasos en la fabricación de los morteros lo impidieron (17); en la fábrica de Chapultepec, por su parte, tuvo lugar un importante incendio que redujo la capacidad de producción a la mitad.

(16) Carta de Salvador Dampierr y José Manuel Varela al coronel Melchor Vidal de Lorca; Chapultepec, 10 de julio de 1782.

(17) Cuando estaba todo listo para la fundición del bronce del que se íban a fabricar los morteros de Santa Fe, la obra se paralizó, por la decisión de sustituirlos por otros de madera con menor riesgo de incendios en la molienda. La madera no estaba disponible, lo que atrasó considerablemente la obra [AGI, México 2216]. 
Ante estas circunstancias, Vidal de Lorca se dirigió a los técnicos en la materia, para que propusiesen soluciones a la alta demanda de pólvora. Uno de ellos fue el ingeniero militar Miguel Constansó, que presentó como solución la reducción del tiempo de molienda de la pólvora a la mitad [AGI, México 1405] (18). Otro fue el teniente de Artillería Luís de Villaba, que propuso el trabajo nocturno en la fábrica y el acuerdo con los contratistas Hoscasitas y Portusach, que poseían dos máquinas para la fabricación de pólvora. La propuesta que se va a analizar procedía del director de salitres Salvador Dampierr y del administrador de la fábrica José Manuel Varela. Para la defensa de la misma elaboraron un estudio de costes, el segundo por orden cronológico localizado en el Archivo de Indias.

Varela y Dampierr estudiaron el coste de producción de la pólvora para demostrar que la habilitación de la fábrica de Santa Fe (estaba cercana la finalización de la misma) era más ventajosa a la Corona que la realización de la contrata con Horcasitas y Portusach. Se manifestaban en contra de la contrata: en primer lugar, por el resultado de la confrontación entre el precio de adquisición de la pólvora de los contratistas y su coste de producción en Santa Fe; en segundo lugar, por dudar de la calidad de la pólvora fabricada en el exterior. Hoscasitas y Portusach se habían encargado, en determinadas ocasiones, de la elaboración de pólvora para el público, cuando la producción íntegra de Chapultepec se había tenido que destinar al servicio real. Se había comprobado que la calidad de esa pólvora no era «admisible para el Uso de la Guerra». Dampierr y Varela temían que esto sucediese con la pólvora del Rey, por el coste de oportunidad que supondría entregar los ingredientes a los contratistas en lugar de utilizarlos en la nueva fábrica (donde la calidad estaba garantizada).

En un plazo de dos meses podía estar finalizada la construcción de los morteros de la nueva fábrica (empleando el bronce disponible para su confección). Incluso se podían ir incorporando a los molinos de pólvora conforme se fueran finalizando, para su utilización progresiva en el proceso productivo. Una vez habilitada la nueva fábrica, la capacidad productiva estimada era de 475 quintales de pólvora al mes, mayor que la que según Villaba entregarían los contratistas (300 quintales). Unida a la producción de Chapultepec, darían un total de 800 quintales mensuales, lo que permitiría abastecer el puerto de Veracruz con 4.000 quintales a primeros de 1782. Además de funcionar las dos fábricas simultáneamente, como en los cinco meses que restaban del año no se alcanzarían los 5.000 quintales de

(18) Carta del ingeniero militar Miguel Constansó al Virrey Martín de Mayorga; México, 16 de marzo de 1781. 
pólvora solicitados, Varela y Dampierr propusieron el trabajo en la fábrica los días festivos, previo permiso de las autoridades eclesiásticas.

Estos dos técnicos consideraban que después de las cuantiosas sumas que había invertido el erario público en la construcción de la nueva fábrica, la decisión de optar por la contrata iría contra los intereses de la Hacienda Real. Elaboraron entonces el siguiente cálculo del coste mensual de producción de la pólvora a fabricar en Santa Fe:

"Corresponden labrarse cada mes con respecto a sus ocho Máquinas de Molinos

COSTOS DEL GRANERO

Por 60 Operarios a 3 reales diarios importan 22 pesos 4 reales, y en los 25 días de trabajo al mes

Por 3 Peones de confianza en los mismos días a 5 reales cada uno

A su Mayordomo 2 p. diarios le corresponden al Mes .. A su Ayudante a 10 r. diarios en dicho tiempo

Molinos

Por 16 Molineros a 1 peso diario, importan en los 25 días de trabajo

A sus Mayordomos, con 12 reales diarios corresponden al Mes

DEPENDIENTES

A un Teniente

A dos Guardas a 12 reales cada uno

A un Portero, 1 peso diario

Por Gastos de Caballeriza, Mozos, Arriero y otros ordinarios de Fábrica se regulan al Mes

Suma

\section{MATERIALES}

Por el costo total de los 475 quintales de Mixtos, a razón de 2.005 pesos cada 100 quintales que pagan los Contratistas

$\frac{9.523 p 4 r}{11.095 p 3 r}$

Los 475 quintales de Pólvora pagados a cuatro y medio reales la libra, importan $26.718 p 6 r$

Resultan cada mes a favor del Rey $15.623 p 3 r$ 
Las partidas de costes que Varela y Dampierr consideraron en la elaboración de su informe incluyen costes directos de producción, tales como los costes de la materia prima y del personal afecto a las tareas de construcción de la pólvora (en el granero y en el molino), y determinadas partidas de costes indirectos, como el coste de algunos dependientes de la fábrica. No se tuvieron en cuenta los costes de administración, ni los ocasionados por el proceso de refinación del salitre (personal de la oficina de coaxaderas, leña, enseres).

De la comparación entre el coste de producción en la fábrica de los 475 quintales de pólvora (11.095 pesos, 3 reales) y el precio de adquisición de esa cantidad de pólvora a los contratistas (26.718 pesos, 6 reales), resultaba un ahorro para el Rey con la primera opción de 15.623 pesos, 3 reales mensuales. A pesar de ello, la decisión final fue a favor de la contrata. El entonces Superintendente de Real Hacienda, D. Pedro Antonio de Cossío, se decantó por esa solución, pues consideraba peligrosa la utilización de los morteros de bronce.

El precio de la libra de pólvora adquirida a’ los contratistas era de 4 reales y medio la libra (aunque estos intentaron subirlo a 6), mientras que el coste de producción de la libra de pólvora, según estos cálculos, ascendía a 1 real y 10 granos (algo menos de 2 reales la libra). El fiscal de Real Hacienda, D. Ramón de Posada, apoyó también la solución de la contrata, siempre y cuando el precio de la pólvora fuera de 4 reales y medio. Con ese precio, los contratistas obtenían unas ganacias de 425.000 pesos para los 12.000 quintales de pólvora que estos se comprometían a fabricar. Es decir, las ganancias ascendían a 2 reales y 9 granos la libra de pólvora (aproximadamente 3 reales), considerándose éste un rendimiento digno y suficiente (alcanzaba el 150 por 100).

Para la aprobación de la contrata, Posada exigía a los contratistas que la pólvora que fabricasen se asemejara en calidad a la de la fábrica real:

«... Cuando así no fuere, la Real Hacienda nada habría perdido, pues en su caso se debería estipular la retención del precio hasta la prueba y examen de la Pólvora que entregaron, conforme a las Ordenanzas, y pasado el tiempo de dos meses por lo menos que prescriben. Y así quedaría vencido el embarazo que para aceptar la contrata origina este principio de no conocer la bondad, virtud y consistencia de la que proponen fabricar» (el subrayado se ha añadido) [AGI, México 2216] (19).

(19) Informe del fiscal de Real Hacienda Don Ramón de Posada; México, 24 de julio de 1781 . 
A pesar de las precauciones, el resultado de la contrata no fue el pretendido, quedando confirmadas las dudas planteadas por Dampierr y Varela. En un informe de un año más tarde (18 de julio de 1782), Posada solicitaba al Virrey la suspensión de la contrata, debido a la escasez de pólvora en La Habana, Veracruz y Cartagena, y a la mala calidad de la suministrada por los contratistas, "... que no sirve al uso de la Artillería". Posada era tajante en su informe, por el coste de oportunidad que suponía el empleo de los ingredientes de la pólvora en las máquinas de los contratistas, en lugar de en las fábricas reales:

«Todo lo que no es suspender estas Máquinas inmediatamente, es consumir los simples con perjuicio evidente del Erario, deshacerse de los que deben habilitar las labores de las Fábricas del Rey, dejar a estos que se dicen contratistas unas ganancias tan cuantiosas, como voluntarias.... [AGI, México 2216].

En julio del año siguiente, 1783, se suspendió la concesión de Horcasitas y Portusach.

\subsection{INTENTO DE INCLUSION DEL CALCULO ANUAL DE COSTES EN LOS INFORMES DE LA RENTA}

En este punto caben resaltar las discusiones surgidas en 1778 entre el Contador General del Consejo de Indias, D. Francisco Machado, el Fiscal del Consejo de Indias, D. José Antonio de Areche y el Tribunal de Cuentas del virreinato de Nueva España. La polémica surgió años antes, en 1774, a raiz de la recepción en el Consejo de Indias de la Cuenta General del año 1772. Tras el análisis de la misma, el entonces Contador General del Consejo, D. Tomás Ortiz de Landazuri, alegó defectos sustanciales que debían ser subsanados antes de su aprobación definitiva o finiquito. Este hecho provocó la apertura de un expediente, actuando como partes los Contadores del Tribunal de Cuentas de Nueva España que habían revisado dichas cuentas, el Fiscal y el Contador General del Consejo de Indias.

La consideración del citado expediente en este apartado se fundamenta en los distintos posicionamientos de las partes implicadas, con respecto a la conveniencia o no de presentar en los informes financieros de la renta, la cifra de 3 reales/libra como precio de venta de la pólvora al Rey. Ese importe no había sido elegido al azar. Se trataba del precio al que el último asentista del ramo vendía la pólvora a la Corona, según estipulaba su contrato de arrendamiento [que a su vez era el 
mismo precio fijado desde 1642 para la pólvora «de gracia» (20)]. El mantenimiento de este precio de venta en los informes financieros permitía la comparación entre los rendimientos obtenidos con el nuevo método con respecto al antiguo.

Los tres reales la libra de pólvora del Rey aparecían en la Cuenta General anual como data de productos, por la parte de la pólvora fabricada destinada al servicio real, y como cargo de caudales (entrada ficticia de caudales en la tesorería, ya que una salida de pólvora debía corresponderse con una entrada de dinero, que en este caso no se producía). A raiz del análisis de la Cuenta anual de 1772, promovido por la apertura del expediente, los Contadores del Tribunal de Cuentas expusieron la conveniencia de modificar este tipo de contabilización, alegando para ello que «... no correspondía la realidad al concepto, toda la vez que no le tenía de costo al Rey los tres reales sino mucho menos» [AGI, México 2228] (21).

Reconocían que con esos registros no se perjudicaba la hacienda, al cargarse y descargarse a un mismo precio, con lo que «... no se alteraba el cargo y descargo de la cuenta». Pero podían producir otro tipo de inconvenientes, siendo el principal de ellos el que las anotaciones contables no reflejasen la realidad. Proponían entonces que la pólvora del Rey (o pólvora en especie, porque no provocaba entrada de caudales) sólo apareciese en los cargos y datas de productos, y que «... al tiempo de presentar las cuentas se purificase en ellas mismas el verdadero costo de la pólvora en especie en el año de la que se presentase» [AGI, México 2228] (22).

Las ventajas que derivaban de la adopción de esta medida eran:

a) el Rey conocería el verdadero coste que le suponían «las expediciones, presidios y fronteras»;

b) las cuentas reflejarían la realidad, al no incluirse unos «cargos y datas imaginarios por virtud del precio ideal de tres reales que se daba a la libra de pólvora»;

c) en caso de que los costes se dispararan algún año, se podrían estudiar la causa de ese aumento desproporcionado para solucio-

(20) Cantidad de pólvora que el asentista se comprometía a entregar anualmente a la Corona, como pago en especie del alquiler de la renta. Aunque la Corona no pagaba nada por estas pólvoras, se les asignaba un precio fijo, que desde 1642 fue de 3 reales la libra [Fonseca y Urrutia, 1845-53].

(21) Informe del Contador General del Consejo de Indias, Don Francisco Machado, sobre el expediente iniciado a raiz de los defectos hallados en la Cuenta General anual correspondiente a 1772; Madrid, 22 de julio de 1778.

(22) Idem. 
narlo, y así «se pudiese precaucionar todo fraude y perjuicio a la Real Hacienda»:

"... si en el discurso de los tiempos se reconociese que la pólvora, sin mejorar la calidad, tenía mucho mayor costo, podría descender el celo al examen de la causa de la alteración, y si provenía por la escasez o carestía de alguno de los simples o ingredientes, o por voluntaria e injusta alteración de precios, o por descuido o malversación del Administrador...” [AGI, México 2228].

El Fiscal del Consejo de Indias, Don José Antonio de Areche, no tuvo en cuenta estas consideraciones propuestas por los Contadores de Cuentas de Nueva España, a pesar del apoyo a las mismas del Contador General del Consejo. Así lo manifestó Machado en su informe, dirigido al Ministro de Indias.

No se han observado modificaciones en las Cuentas Generales presentadas en años posteriores (excepto la ya comentada introducción de la partida doble los años 1786 y 1787), ni tampoco se han localizado otros estudios de costes posteriores. De ello se deduce que la propuesta del Tribunal de Cuentas de Nueva España y del Contador General Machado no prosperó, y no se incorporó el cálculo anual de costes a los informes financieros de la renta.

\section{A MODO DE RESUMEN}

Como señalábamos en el epígrafe anterior, la realización de estudios sobre costes en la renta de la pólvora, tras el paso al régimen de gestión estatal directa, no constituye un hecho sistemático, en cuanto a su transcendencia ante instituciones superiores (Consejo de Indias o Tribunal de Cuentas de Nueva España). Su aparición se relaciona en cambio con la justificación de la adopción de una determinada medida o de la actuación de un funcionario responsable.

En el caso considerado, la obligación de presentación de estados contables detallados ante la implantación del nuevo sistema de administración de la renta, proporcionó a la contabilidad el papel de modelo de visibilidad organizativa. Los estados contables suministraron la información de la que hasta entonces se había carecido, lo que permitió guiar las actuaciones en la renta y corregir las desviaciones con respecto a lo reglamentado. 
Pero habría que especificar que la contabilidad actuó como modelo de visibilidad organizativa en función de las necesidades de información y del nivel considerado, tal como se puede extraer de los estudios de costes analizados. A nivel de la renta, se disponía de la tecnología contable necesaria para el cálculo anual del coste de producción de la pólvora. Asimismo, las instituciones de control de la metrópoli y colonia eran partidarias de la incorporación de dicho cálculo a los informes anuales reportados. A pesar de ello, la medida no se implantó. Esa información resultaba irrelevante a niveles superiores (Superintendencia General de Real Hacienda del Reino: Dirección General de Rentas). A estas instancias, la importancia residía en el conocimiento de los rendimientos generados por la renta de Nueva España y la certeza de que los caudales ingresados en la Depositaría General de Indias (Cádiz) eran los correctos.

No obstante, a partir de las fuentes primarias consultadas se puede deducir que a nivel de fábrica calculaban dicho coste, aunque sólo trascendiera a las instituciones de control señaladas como consecuencia de conflictos específicos.

\section{BIBLIOGRAFÍA}

ArcIla FarIas, E. [1955]: El Siglo Ilustrado en América: Reformas Económicas del Siglo XVIII en Nueva España (Ediciones del Ministerio de Educación: Caracas).

Artola, M. [1982]: La Hacienda del Antiguo Régimen. Alianza Universidad Textos (Alianza Editorial: Madrid).

ARchivo General de Indias: Audiencia de México, legajos: 1013, 1249, 1405, 2216, $2228,2235,2450$.

Bargallo, M. [1955]: La minería y la metalurgia en la América española durante la época colonial (Fondo de Cultura Económica: México).

Donoso Anes, A. [1996]: La Contabilidad Virreinal Americana, Análisis de una Experiencia: La Aplicación del Método de la Partida Doble en las Reales Cajas de Indias (1784-1787). Tesis Doctoral no publicada. Universidad de Sevilla.

FonseCA, F., y UrRUTIA, C. [1845-53]: Historia General de la Real Hacienda en Nueva España. 6 volúmenes (Imp. Vicente G. Torres: México).

GonZaLEZ TASCON, I. [1992]: Ingeniería española en ultramar: siglos XVI-XIX, vol. 1 (Tabapress, S.A.: Sevilla).

GRAN EnCICLOPEDIA DEL Mundo [1982]: 2. ${ }^{a}$ edición (Editorial Marín, S.A.: Barcelona).

Hernandez Esteve, E. [1992]: Problemática general de una Historia de la Contabilidad en España. Revisión genérica de las modernas corrientes epistemológicas, metodológicas y cuestiones específicas. Ponencia presentada en el Encuentro 
de Trabajo sobre la elaboración de una Historia de la Contabilidad en España (COTM y E., AECA, UAM: Madrid).

Recopilación de las Leyes de los Reinos de las Indias mandadas escribir y publicar por la Majestad Católica del Rey Don Carlos II [1681]. Reproducción en facsímil en 1973 de la edición de Julián Paredes. Prólogo de Ramón Menéndez y Pidal y estudio preliminar de Juan Manzano Manzano. 4 tomos (Editorial Cultura Hispánica: Madrid).

Villar OrTiz, C. [1988]: La renta de la pólvora en Nueva España (1569-1767) (Escuela de Estudios Hispano-Americanos: Sevilla). 